\section{Apricot-Stone Syndrome (Barackmag-Syndrome): A Report of Two Cases}

We present two peculiar cases of ingested apricot stones discovered as foreign bodies in the stomach and the rectum.

Case 1: A 55-year-old female patient complaining of epigastric pain, vomiting, and loss of weight underwent upper panendoscopy. During the examination, after opening of the pyloric ring a darkbrown object, an apricot stone, spontaneously moved backward into the stomach (Figure 1). The stenotic bulb with diverticular hollows retained the stone causing occasional obstruction. After successful retrieval (Figure 2 ), the patient remembered accidentally swallowing an apricot stone one month earlier. Case 2: Just after apricot season one year later, a 70-year-old female patient underwent surgery for mechanical ileus. Sigmoidostomy was performed leaving the tumorous part of the rectosigmoid colon untouched. An inflammation was diagnosed by rigid rectoscopies. One month later, before the planned reconstruction, during the preoperative colonoscopy it was a surprise when we extracted a large apricot stone from the tumor-free rectal sack. The patient recalled having swallowed the stone. She felt well for weeks thereafter and her favorable condition was confirmed by her family doctor. The incident had been completely forgotten by the time of surgery.

Most foreign bodies swallowed involuntarily can pass the digestive tract without notice, but the natural passage time is unpredictable (1). An ingested object may be tolerated for a long period but may require endoscopic or surgical intervention because of sudden complications (2). Detection of small seeds is common during routine endoscopy, but unexpected discovery of large fruit stones is unusual. Since the ingestion is often forgotten, Barackmag-Syndrome should be kept in mind particularly during apricot season (July and August for the Hungarian apricot, Gönci magyar kajszi) and when symptoms of intestinal obstruction exist. Skillful endoscopic extraction can solve the problem in most cases.

\section{A. Kazsuba' , I. Gyôri ${ }^{2}$, J. Ferencz ${ }^{3}$}

'Department of Gastroenterology, Erzsébet Hospital, Jászberény, Hungary;

${ }^{2}$ II. Department of Internal Medicine, and

${ }^{3}$ Department of Surgery, Bugát Pál Hospital, Gyöngyös, Hungary

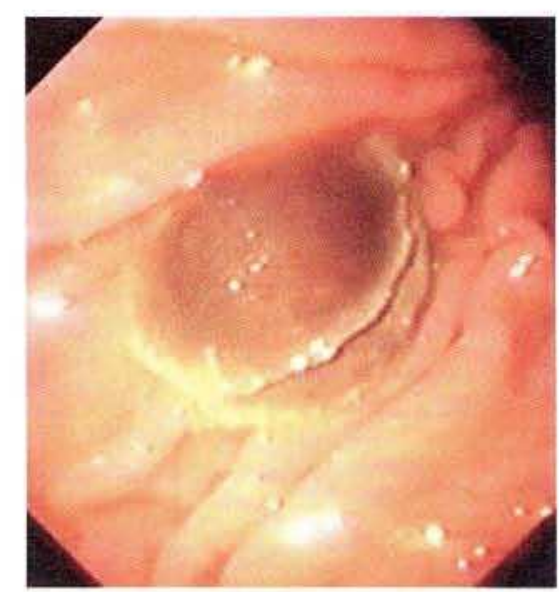

Figure 1: Endoscopic view of the apricot stone in the stomach.

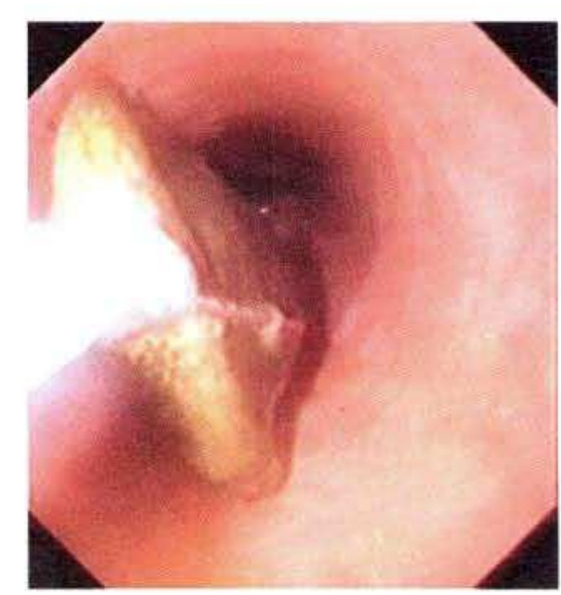

\section{References}

1. Manegold BC: Endoscopic extraction of foreign bodies from the digestive tract. In: Pronai G, Wittman I (eds): Current views in digestive endoscopy. Hungarian Society of Gastroenterology, Budapest, 1978, 87-96.

2. Hamilton JK, Polter DE: Gastrointestinal foreign bodies. In: Sleisenger MH, Fordtran JS (eds): Gastrointestinal Disease. Saunders, Philadelphia 1993; Chapter 12: 286-292

Corresponding Author

Attila Kazsuba, M.D.

Department of Gastroenterology

Erzsébet Hospital

5100 Jászberény

Hungary
Figure 2: The stone grasped with a polypectomy snare during retrieval in the upper part of the esophagus. 